\title{
Patient Profiles of Pott's Diseases: Experience of 50 Cases in a Tertiary Care Hospital in Dhaka City
}

\author{
Md. Shafiul Alam¹, Amir Mohammad Khan², Tayseer Farzana ${ }^{3}$, \\ Md. Abdus Salam 4 , Abdur Rabban Talukder ${ }^{5}$ \\ ${ }^{1}$ Assistant Professor, Department of Gamma Knife Neurosurgery, National Institute of Neurosciences, Bangladesh; \\ ${ }^{2}$ Assistant Professor, Department of Neurosurgery, National Institute of Neurosciences, Bangladesh; \\ ${ }^{3}$ Consultant, Department of Radiology and Imaging, Popular Diagnostic Center, Mirpur Branch, Dhaka, \\ Bangladesh; ${ }^{4}$ Associate Professor, Department of Neurotrauma Surgery, National Institute of \\ Neurosciences \& Hospital, Dhaka, Bangladesh; ${ }^{5}$ Assistant Professor, Department of Surgery, \\ Shaheed M. Monsur Ali Medical College, Sirajganj, Bangladesh
}

[Received: 21 January 2016; Revised: 6 March 2016; Accepted: 11 June 2016; Published: 1 July 2016]

\begin{abstract}
Background: Spinal tuberculosis is a great problem in the health sector. Objective: The purpose of the present study was to see the see the socio-demographic characteristics of spinal tuberculosis patients. Methodology: This study was designed as descriptive cross sectional study which was carried out in the Department of Neurosurgery at Dhaka Medical College Hospital during the period of January 2002 to December 2004 for a period of two (2) years. All the patients who were presented with spinal tuberculosis at any age with both sexes were included as study population. The details of socio-economic condition were recorded of all the patients. Confirmation of spinal tuberculosis was made by CT-scan and MRI. Finally biopsy was done to confirm the cases by histopathology. Results: In this study, 50 cases of tuberculosis of the spine patients were recruited for this study. The mean age with SD was $25.4 \pm 18.65$ years. The sex distribution shows male preponderance with a male and female ratio of 1.63:1. Regarding the socioeconomic status $33(66 \%)$ patients came from low class society. In this study majority of the study population were illiterate which was $19(38.0 \%)$ cases. Most of the patients were day labourer which was $17(34.0 \%)$ cases. Conclusion: In conclusion young adult male patients are most commonly affected by spinal tuberculosis. [Journal of National Institute of Neurosciences Bangladesh, 2016;2(2): 48-50]
\end{abstract}

Keywords: Socio-demographic characteristics; Pott's disease; spinal tuberculosis; Mycobacterium tuberculosis

Correspondence: Dr. Shafiul Alam, Assistant Professor, Department of Neurosurgery, National Institute of Neurosciences \& Hospital, Dhaka, Bangladesh; Email: dr_chapal@hotmail.com; Cell no.: +8801711567358

Conflict of interest: There is no conflict of interest relevant to this paper to disclose.

Funding agency: This research project was not funded by any group or any institution.

Contribution to authors: MSA, AMK \& MAS were involved in protocol preparation, data collection and literature search up to manuscript writing. TF \& ART were involved in preparation and revision of this manuscript.

How to cite this article: Alam MS, Khan AM, Farzana T, Salam MA, Talukder AR. Patient Profiles of Pott's Diseases: Experience of 50 Cases in a Tertiary Care Hospital in Dhaka City. J Natl Inst Neurosci Bangladesh, 2016;2(2): 48-50

Copyright: (C2016 Alam et al. Published by Journal of National Institute of Neurosciences Bangladesh. This article is published under the Creative Commons CC BY-NC License (https://creativecommons.org/licenses/by-nc/4.0/). This license permits use, distribution and reproduction in any medium, provided the original work is properly cited, and is not used for commercial purposes.

\section{Introduction}

Tuberculosis of the spine is one of the oldest diseases afflicting humans ${ }^{1}$. Tuberculosis was a leading cause of mortality in the beginning of the twentieth century ${ }^{2}$. The descriptions in Rigveda, Atharvaveda and Charak Samhita are the oldest known texts in the world literature relating to this disease. The association of paraplegia and kyphotic deformity of the spine was first noticed by Sir Percival Pott ${ }^{2}$. Improvement in the socio-economic status led to a major decline in the prevalence even before the introduction of antituberculous drugs ${ }^{3}$. However, it continues to be a major public health problem in developing countries. Malnutrition, poor sanitation and exanthematous fever 
are the factors contributing to the spread of the disease $\mathrm{e}^{4}$. In the United States, there has been a steady increase in the prevalence of pulmonary as well as extrapulmonary tuberculosis and this is largely due to impairment of immune system by the human immunodeficiency virus leading to reactivation of latent infection and a likelihood of progression to active disease ${ }^{5}$. In Bangladesh the scenario is not good ${ }^{6}$. The reason of this may be due to lack of hygiene, poor living status and so one. In this context this present study was undertaken to see the socio-demographic characteristics of spinal tuberculosis patients.

\section{Methodology}

This was a cross-sectional study. The study was carried out in the Department of Neurosurgery at Dhaka Medical College Hospital, Dhaka, Bangladesh. The study was conducted during the period of January 2003 to December 2004 for a period of two (2) years. The study was purposive. All patients who were admitted with the diagnosis of spinal tuberculosis were included in the study. Patients with history of spinal injury were excluded from the study. A protocol was prepared by the researcher with key variables like age and sex of the patient, socio-economic status. The data was collected by the researcher himself. Prior to commencement of this study, the research protocol was approved. The aims and objectives of the study along with its procedure, alternative diagnostic methods, risks and benefits of this study were explained to the patients in easily understandable language and then informed consent was taken from each patient. Statistical analysis was performed by Windows based software Statistical Packages for Social Sciences (SPSS 16.0). The qualitative variables were expressed as frequency and percentage and quantitative variable were expressed ad mean and standard deviation.

\section{Results}

In this study, 50 cases of tuberculosis of the spine showed the age range from 7 years to 68 years with the highest incidence in the first three decades $(70 \%)$ of life. The peak incidence was in the second decade (34\%). The mean age was 25.4 years with $\mathrm{SD} \pm 18.65$ years (Table 1 ).

Table 1: Distribution of patients by age $(n=50)$

\begin{tabular}{lcc}
\hline Age Group & Frequency & Percentage \\
\hline 0 to 20 Years & 21 & 42.0 \\
21 to 40 Years & 21 & 42.0 \\
41 to 60 Years & 7 & 14.0 \\
More than 61 Years & 1 & 2.0 \\
\hline Total & $\mathbf{5 0}$ & $\mathbf{1 0 0 . 0}$ \\
\hline
\end{tabular}

The sex distribution shows male preponderance. Among 50 patients $31(62 \%)$ were male and $19(38 \%)$ were female. Male female ratio was 1.63: 1 (Table 2).

Table 2: Distribution of patients by Sex $(n=50)$

\begin{tabular}{lcc}
\hline Gender & Frequency & Percentage \\
\hline Male & 31 & 62.0 \\
Female & 19 & 38.0 \\
\hline Total & $\mathbf{5 0}$ & $\mathbf{1 0 0 . 0}$ \\
\hline
\end{tabular}

Regarding the socioeconomic status $33(66 \%)$ patients came from low class society, $14(28 \%)$ came from middle class society and $3(6 \%)$ came from upper class society (Table 3 ).

Table 3: Distribution of patients by Socio-economic status $(\mathrm{n}=50)$

\begin{tabular}{lcc}
\hline SE Condition & Frequency & Percentage \\
\hline Upper class & 3 & 6 \\
Middle class & 14 & 28 \\
Low class & 33 & 66 \\
\hline Total & $\mathbf{5 0}$ & $\mathbf{1 0 0 . 0}$ \\
\hline
\end{tabular}

In this study majority of the study population were illiterate which was $19(38.0 \%)$ cases followed by primary and SSC level which were $15(30.0 \%)$ and $11(22.0 \%)$ cases respectively. Only $5(10.0 \%)$ cases were graduate (Table 4).

Table 4: Educational Status of the Study Population $(\mathrm{n}=50)$

\begin{tabular}{lcc}
\hline Educational Status & Frequency & Percentage \\
\hline Illiterate & 19 & 38.0 \\
Primary & 15 & 30.0 \\
HSC & 11 & 22.0 \\
Graduate & 5 & 10.0 \\
\hline Total & $\mathbf{5 0}$ & $\mathbf{1 0 0 . 0}$ \\
\hline
\end{tabular}

Patients with different occupation were affected by spinal tuberculosis. Most of the patients were day labourer which was $17(34.0 \%)$ cases followed by housewife, service holder and students which were $13(26.0 \%)$ cases, $9(18.0 \%)$ cases and $6(12.0 \%)$ cases respectively (Table 5).

Table 5: Occupational Status of the Study Population $(\mathrm{n}=50)$

\begin{tabular}{lcc}
\hline Occupational Status & Frequency & Percentage \\
\hline Day Labourer & 17 & 34.0 \\
Housewife & 13 & 26.0 \\
Service & 9 & 18.0 \\
Students & 6 & 12.0 \\
Others & 5 & 10.0 \\
\hline Total & $\mathbf{5 0}$ & $\mathbf{1 0 0 . 0}$ \\
\hline
\end{tabular}




\section{Discussion}

In this study, 50 cases of tuberculosis of the spine showed the age range from 7 years to 68 years with the highest incidence in the first three decades $(70 \%)$ of life. The peak incidence was in the second decade (34\%). The mean age was 25.4 years with $\mathrm{SD} \pm 18.65$ years. Spinal tuberculosis may occur at any age but most common during first three decades of life. In this series age was 25.4 years and ranged from 7 years to 68 years. The highest incidence was in first three decades $(70 \%)$ of life. Dass et $\mathrm{al}^{7}$ series also shows highest incidence in first three decades of life and it is $73 \%$ cases. Currently there is a tendency of involvement of adult age group particularly in the developed countries due to high incidence of AIDS, intravenous drug abuse and other causes of immune suppression ${ }^{8}$.

Extrapulmonary tuberculosis is more common in children than in adults ${ }^{8}$. The commonest site is being the superficial lymph nodes. A minimum time lag of 2 to 3 years is present between the development of primary focus and manifestation of the disease in the spine ${ }^{9}$. The bacteria may reach the spine through the arterial circulation or the Batson's plexus of veins. Initially, two contiguous vertebral bodies are involved due to a common vascular supply. Destruction of vertebral bodes compromises the nutrition of the intervertebral disc and leads to progressive disc destruction and vertebral collapse ${ }^{10}$. In Bangladesh spinal tuberculosis is predominantly a disease of the young and the usual age of presentation is the first three decades of life ${ }^{11}$ which is consistent with the present study result. Reports from developed countries indicate a much older patient population and the median age at diagnosis being sixty-one years.

The disease is equally distributed among both sexes. But our series showed male preponderance. The male female ratio was 1.63:1. In most series, the disease has been found to affect males and females in equal proportions $^{12}$.This may be due to male people are more active and expose to external environment in this country. Tuberculosis is a disease of low socio-economic group. Malnutrition, illiteracy and poor hygienic conditions are responsible for this ${ }^{8}$. This present study also showed that most of the patients came from low class society. It indicates that people require more awareness about nutrition and hygiene to prevent tuberculosis ${ }^{13}$.

Spinal tuberculosis is a destructive form of tuberculosis ${ }^{2}$. It accounts for approximately half of all cases of musculoskeletal tuberculosis ${ }^{6}$. The incidence of spinal tuberculosis is increasing in developed nations like Bangladesh. Genetic susceptibility to spinal tuberculosis has recently been demonstrated ${ }^{2}$. Proper diagnosis and management is a necessary thing to tackle the situation.

\section{Conclusion}

In conclusion young adult age group is most commonly affected by spinal tuberculosis. However male is predominantly suffering from spinal tuberculosis. Low socio-economic condition and illiterate people are mostly presented with spinal tuberculosis. Public awareness should be generated regarding this communicable and preventable disease like tuberculosis.

\section{References}

1. Dharmalingam M. Tuberculosis of the spine - the Sabah experience. Epidemiology, treatment and results. Tuberculosis 2004;84(1):24-8

2. Garg RK, Somvanshi DS. Spinal tuberculosis: a review. The Journal of Spinal Cord Medicine 2011;34(5):440-54

3. Pertuiset E, Beaudreuil J, Lioté F, Horusitzky A, Kemiche F, Richette P, Clerc-Wyel D, Cerf-Payrastre I, Dorfmann H, Glowinski J, Crouzet J. Spinal Tuberculosis in Adults: A Study of 103 Cases in a Developed Country, 1980-1994. Medicine. 1999;78(5):309-20

4. Trecarichi EM, Di Meco E, Mazzotta VA, Fantoni MA. Tuberculous spondylodiscitis: epidemiology, clinical features, treatment, and outcome. Eur Rev Med Pharmacol Sci 2012;16(Suppl 2):58-72

5. Davda P, Bharucha T, Murugachandran J, Palchaudhuri P. Epidemiology and clinical management of spinal tuberculosis (TB) at a south-east London hospital. European Res J 2014;44(Suppl 58):P1440

6. Turgut M. Spinal tuberculosis (Pott's disease): its clinical presentation, surgical management, and outcome. A survey study on 694 patients. Neurosur Rev 2001;24(1):8-13

7. Dass B, Puet TA, Watanakunakorn C. Tuberculosis of the spine (Pott's disease) presenting as' compression fractures'. Spinal Cord 2002;40(11):604-8

8. Bagalkot P, Anagdi B, Joshi S. Spinal tuberculosis in children: retrospective analysis of 124 patients. Indian J Orthopaed 2012;46(6):728

9. Rasouli MR, Mirkoohi M, Vaccaro AR, Yarandi KK, Rahimi-Movaghar V. Spinal tuberculosis: diagnosis and management. Asian Spine J 2012;6(4):294-308

10. Al-Hajoj S, Shoukri M, Memish Z, AlHakeem R, AlRabiah F, Varghese B. Exploring the socio-demographic and clinical features of extrapulmonary tuberculosis in saudi arabia. PloS One 2015;10(2):e0101667

11. Mondal MN, Nazrul HM, Chowdhury MR, Howard J. Socio-demographic factors affecting knowledge level of Tuberculosis patients in Rajshahi City, Bangladesh. African Health Sci 2014;14(4):855-65

12. Jin D, Qu D, Chen J, Zhang H. One-stage anterior interbody autografting and instrumentation in primary surgical management of thoracolumbar spinal tuberculosis. European Spine J 2004;13(2):114-21

13. Millet JP, Moreno A, Fina L, Del Baño L, Orcau A, de Olalla PG, Caylà JA. Factors that influence current tuberculosis epidemiology. European Spine J 2013;22(4):539-48 